\title{
Optimization of the process variables in the microwave-induced synthesis of carbon xerogels
}

\author{
Natalia Rey-Raap ${ }^{\mathrm{a}}$, J. Angel Menéndez ${ }^{\mathrm{a}}$, Ana Arenillas, ${ }^{\mathrm{a}}$ ** \\ a Instituto Nacional del Carbón, CSIC, Apartado 73, 33080 Oviedo, Spain \\ *Corresponding autor: aapuente@incar.csic.es; Tel: +34 985119090; Fax: \\ $+34985297662$
}

\begin{abstract}
Carbon xerogels can be synthesized by microwave-assisted heating. The transfer of this technology to an industrial scale passes through the optimization of the variables that affect the process. The effect of the main operational variables, i.e., initial volume of the precursor, gelation and ageing time and temperature of the synthesis, on the final porous properties of carbon xerogels has been evaluated. It was found that the development of porosity in the carbon xerogels synthesised in the microwave oven is hardly influenced by the increase in the initial volume of the precursor solution. This suggests that it is feasible to scale up the production of these materials by means of microwave heating. Furthermore, the consumption of energy does not increase in proportion to the volume of xerogel synthesized. Thus, the process is energy efficient, saves a considerable amount of time and requires only a single device to carry it out. These advantages, along with the fact that a temperature variation of $10^{\circ} \mathrm{C}$ is not determinative in the xerogels' final properties, indicate that carbon xerogels could be produced on a large scale in a cost effective way.
\end{abstract}

Keywords: microwave; temperature; carbon gels; gelation time; gelation point; pore size distribution

\section{Introduction}

Carbon gels are porous materials that are prepared by drying and carbonizing organic polymer-based gels [1]. One of the advantages of these materials is that it is possible to design their porosity and chemical properties provided that the synthesis conditions are correctly chosen [2]. Using an appropriate preparation method it is possible to tailor materials for a specific application. For this reason, over the last decade, carbon gels 
have been studied in a wide range of fields including adsorption [3,4], thermal insulation [5,6], catalyst supports [7,8], supercapacitors [9,10], fuel cells [11,12], batteries $[13,14]$, etc.

Nowadays, the most common process used to synthesize carbon gels is based on Pekala's method [15]. The synthesis involves a sol-gel reaction between resorcinol and formaldehyde in an aqueous medium containing sodium carbonate as catalyst followed by a drying stage. Three major types of drying methods can be found in the bibliography: drying under supercritical conditions [16-18], freeze-drying [19,20] and evaporative drying [21]. The dried gel is then subjected to secondary treatments (pyrolysis, activation, etc.) in order to obtain the final carbon gel [22-25].

The main drawback of this conventional method is the long time required for the synthesis, making the production process expensive and uncompetitive. Because of this, the synthesis method of carbon gels has been studied in depth by several research groups. Quin et al. reported a semi-continuous drying process for the synthesis of carbon aerogels. They simplified the production process by eliminating the step of solvent and liquid carbon dioxide exchange [26]. An alternative drying step by means of microwave heating has been studied in order to simplify the process and to reduce time and associated costs [27]. Ultrasonic irradiation has also been considered as a complementary technique for the synthesis of carbon xerogel [28]. Despite these improvements, several days are still required for the synthesis which is an obstacle to industrial scaling up. In 2011 a method that reduces the synthesis time by as much as 95\% was reported by Calvo et al. This method involves microwave radiation heating instead of conventional heating, allowing carbon gels with similar characteristics to those synthesized by the conventional method to be produced more quickly [29].

It is well known that the structure of carbon gels is sensitive to variations in the synthesis and processing conditions [30]. Hence, the effect of such variations on the final porous properties must be determined, especially if the objective is to optimise the process for large-scale carbon gel production. Several works published in the literature on the conventional method allude to the influence of the precursor concentration [2,31], the temperature of synthesis [32,33], ageing time [34], drying and pyrolysis conditions $[35,36]$, etc. However, there is a lack of knowledge on how the final porous 
properties are affected when microwave-assisted synthesis is applied. This process differs in that the heating is volumetric and involves the interaction of the materials with the microwaves, instead of convection as in conventional ovens. It is therefore necessary to know whether microwave heating technology is susceptible to the variation of operating conditions and, if so, the degree of this dependence.

Accordingly, the aim of this work was to study the influence of the operational variables of the microwave-assisted synthesis process, such as the initial volume of precursor solution, gelation and ageing time and temperature of synthesis, on the final porous properties of carbon xerogels. Optimization of these variables will contribute to the transfer of microwave-assisted technology for the production of carbon xerogels to an industrial scale.

\section{Experimental}

\subsection{Preparation of precursor solutions}

Organic gels were synthesized by the polycondensation of resorcinol (R) and formaldehyde (F) using deionized water as solvent and sodium hydroxide as catalyst. Resorcinol (Indspec, 99\%) was first dissolved in deionized water in an unsealed glass beaker under magnetic stirring. After dissolution, formaldehyde (Ercros, 37wt. \% in water, stabilized by $10-15 \%$ methanol) was added and the mixture was stirred until a homogeneous solution was obtained. Finally, the initial $\mathrm{pH}$ value was adjusted by adding sodium hydroxide.

In all cases, the precursor solutions were synthesized using the stoichiometric R/F molar ratio (i.e., 0.5) and a dilution ratio (D) fixed at 5.7. The dilution ratio parameter is defined as the molar ratio between the total solvent and reactants. Total solvent refers to the water and methanol contained in the formaldehyde and the deionized water that is added, whilst reactants refer to the resorcinol and formaldehyde. All the carbon xerogels were synthesized using the same precursor solution $\mathrm{pH}$, i.e. 6.5, as the aim was to evaluate the influence of the operating variables in the microwave device, i.e. temperature, time and initial volume, and not the chemical variables. However, other different $\mathrm{pH}$ values were also tested and the conclusions drawn from this study were valid for this entire range of $\mathrm{pH}$ values studied. 


\subsection{Synthesis conditions}

Three different initial volumes of precursor solution were prepared in order to study their effect on the porous properties of the organic and carbon xerogels: 30, 200 and $3000 \mathrm{ml}$. Each solution was placed in a microwave oven at $85{ }^{\circ} \mathrm{C}$ for 10000 seconds to undergo the gelation and ageing stages. At these stages a PID controller modulates de power delivered by the magnetron to the appropriate fraction of is maximum power (i.e., 700 watts) in order to keep constant the settled temperature. $200 \mathrm{ml}$ was selected as the most appropriate volume for studying the influence of other variables e.g., temperature or time.

The synthesis temperatures were chosen bearing in mind that: it is not advisable to set the temperature too close to the temperature of boiling water and that temperatures below $60^{\circ} \mathrm{C}$ lead to a significant increase in the gelation time and in the cost of the process. This has already been reported for conventional procedures [34] and corroborated in the laboratory for microwave-assisted synthesis. Hence, the optimum temperature is between $70^{\circ} \mathrm{C}$ and $90^{\circ} \mathrm{C} .75^{\circ} \mathrm{C}$ and $85^{\circ} \mathrm{C}$ were chosen as the temperatures for this study.

The time of the synthesis of the organic xerogels, $t_{s}$, includes the gelation, ageing and drying stages. In this study, the time of synthesis was divided into two different variables: the time required for the sol-gel reactions and ageing, $t_{\mathrm{g}-\mathrm{a}}$, and the time needed to dry the excess solvent, $t_{d}$. Three values of $t_{g-a}$ were tested: 2000,6000 and 10000 seconds. After the formation of the polymeric structure, excess water was eliminated by continuing to heat the gel in the same microwave oven for a longer time, $t_{d}$, which will depend on the type of porous structure created. This drying step was conducted until a mass loss of over $50 \%$ was achieved.

\subsection{Microwave heating}

During the synthesis process the material evolves and changes its dielectric properties [37]. These changes lead to a variation in its microwave absorption capacity and therefore in the energy consumed by the equipment to maintain the programmed temperature. Consequently, by monitoring the energy consumed by the microwave oven during the gelation and ageing stages it is possible to identify the transformations that 
take place during the synthesis of the organic xerogels [38]. In this study, a microwave device equipped with a power meter was used to measure the amount of energy consumed by the equipment during the gelation and ageing stages $\left(\mathrm{t}_{\mathrm{g}-\mathrm{a}}\right)$ as explained elsewhere [38].

\subsection{Preparation of the carbon xerogel}

Carbon xerogels (CX) were obtained by the pyrolysis of organic xerogels (OX). The operational conditions were fixed as reported elsewhere [39]. Briefly, the pyrolysis processes were performed in a horizontal tubular furnace at $700{ }^{\circ} \mathrm{C}$ under a nitrogen flow of $500 \mathrm{ml} / \mathrm{min}$. The residence time was 2 hours and the heating rate was set at 50 ${ }^{\circ} \mathrm{C} / \mathrm{min}$.

\subsection{Porous texture characterization}

The porous texture of the organic and carbon gels was characterized by the analysis of nitrogen adsorption-desorption isotherms at $-196{ }^{\circ} \mathrm{C}$ using a Micromeritics Tristar 3000 instrument. The specific surface area $\left(\mathrm{S}_{\mathrm{BET}}\right)$ was evaluated by means of the BET equation, the micropore volume $\left(\mathrm{V}_{\mathrm{DUB}}\right)$ was determined by applying the DubinninRaduskevich method to the nitrogen adsorption isotherms and the pore volume $\left(\mathrm{V}_{\mathrm{P}}\right)$ was calculated from the volume adsorbed at saturation point.

\subsection{Statistical study}

The response surface method (RSM), in the form of central composite design (CCD), was applied in order to evaluate the effects of two of the synthesis conditions selected: temperature and $t_{\mathrm{g}-\mathrm{a}}$. The experimental design approach and the response surface method were applied by using Design-Expert 8.0.7.1 Trial software. The experiments were randomized to validate the statistical results. The micropore volume $\left(\mathrm{V}_{\mathrm{DUB}}\right)$, pore volume $\left(V_{P}\right)$ and pore size $\left(D_{P}\right)$ were selected as the responses of the system while the two process parameters, temperature and $\mathrm{t}_{\mathrm{g}-\mathrm{a}}$, were fixed as input variables.

\subsection{Sample nomenclature}

Throughout the paper, the samples were labelled as follows. The letters OX and CX refer to the organic and carbon xerogel, respectively. These are followed by three different numbers separated by hyphens that correspond respectively to: i) the initial volume, ii) gelation and ageing time and iii) temperature of synthesis. For example, the 
label CX-200-6000-75 corresponds to a carbon xerogel synthesized from 200ml of precursor solution at a $\mathrm{t}_{\mathrm{g}-\mathrm{a}}$ of 6000 seconds at $75^{\circ} \mathrm{C}$.

\section{Results}

\subsection{Influence of the initial volume of precursor solution}

The nitrogen adsorption-desorption isotherms of the organic xerogels prepared using different initial volumes of precursor solution with a $\mathrm{pH}$ of 6.5, and their carbonised counterparts are shown in Figures 1a and 1b, respectively. The samples shown were synthesized at a $\mathrm{tg}_{\mathrm{g}-\mathrm{a}}$ of 10000 seconds at $85^{\circ} \mathrm{C}$ in order to ensure completion of the gelation and ageing stages.

Figure 1a exhibits isotherms of type IV according to the International Union of Pure and Applied Chemistry (IUPAC) classification, corresponding to mesoporous materials. The organic xerogel synthesized from $30 \mathrm{ml}$ of initial solution presents an isotherm with a low volume of nitrogen adsorbed at low relative pressures, which indicates the presence of a small volume of micropores. Furthermore, the nitrogen adsorbed at high relative pressures is also low because of the presence of mesopores of small size. Samples OX200-10000-85 and OX-3000-10000-85 exhibit isotherms that are almost superimposed, suggesting that porous development is not proportional to the increase in the initial volume of precursor solution.

The adsorption-desorption isotherms of the carbonised samples correspond to an isotherm combination of type I and type IV according to the IUPAC classification, indicating that they are micro/mesoporous materials (Figure 1b). These samples exhibit the same trend as their corresponding organic xerogels (Figure 1a). That is to say CX30-10000-85 presents the least developed structure and samples CX-200-10000-85 and CX-3000-10000-85 exhibit similar porous structures, as can be seen from Table 1.

Figure 2a and Figure $2 \mathrm{~b}$ show marked differences between the pore size distribution of the organic and carbon xerogels. Thus, the micropore volumes increase notably after carbonization, whereas the mesopore size distributions seem to be narrower, although for all samples, the average pore diameter is around 8-9nm. 
The fact that samples synthesized from 200 and 3000ml of precursor solution exhibit similar porous structures favours the transfer of microwave-assisted technology for the production of carbon xerogels to an industrial scale. However, a study of the energy consumed by the microwave is needed to perform the scaling-up. In this work, the amount of energy consumed throughout the gelation and ageing stages $\left(t_{g-a}\right)$ was measured by a power meter connected to the microwave device. Greater initial volumes of precursor require a higher energy supply for the gelation and ageing stages to be completed, due to the fact that a longer time is needed to reach the programmed temperature, as can be seen from Table 2. Nevertheless, the microwave energy consumed per volume unit decreases as the initial volume of precursor increases. Initially, as the energy consumed per volume unit decreases, the development of porosity enhanced. However, a decrease to below $1100 \mathrm{~kJ} / \mathrm{l}$ in the amount of microwave energy consumed will not lead to any further development of porosity. Therefore, in order to optimize the synthesis process the optimum ratio between the energy consumed per volume unit and the porous structure obtained needs to be established.

\subsection{Influence of gelation and ageing time}

Figures $3 a$ and $3 b$ show the $\mathrm{N}_{2}$ adsorption-desorption isotherms of the carbon xerogels synthesized at $75^{\circ} \mathrm{C}$ and $85^{\circ} \mathrm{C}$, respectively, for three different values of $\mathrm{t}_{\mathrm{g}-\mathrm{a}}$. All the isotherms are a combination of type I and type IV according to the IUPAC classification, indicating that these samples correspond to micro/mesoporous materials.

The curves are almost superimposed up to a relative pressure of 0.4 , indicating that all the samples have a similar microporosity. At both synthesis temperatures, the isotherms of the samples with a $t_{\text {g-a }}$ of 6000 seconds exhibit an increase in the volume of nitrogen adsorbed at relative pressures above 0.8, which results in materials with a higher volume of mesopores.

The accumulative energy consumed by the microwave device was measured as a function of gelation and ageing time $\left(\mathrm{t}_{\mathrm{g}-\mathrm{a}}\right)$. As mentioned elsewhere, the representation of energy consumed vs. time allows the gelation point to be established [38]. This time was also determined by visual observation. Both values are presented in Table 3. From these data it can be inferred that, under the conditions studied, the gelation times recorded visually were larger than those obtained by measuring the energy 
consumption. This is due to the fact that the transition from sol to gel occurs gradually, making visual determination very difficult and inaccurate.

All the samples studied were subjected to an exclusive drying stage at $85^{\circ} \mathrm{C}$ after synthesis, until a mass loss of more than $50 \%$ was achieved. The time needed for drying is also provided in Table 3.

\subsection{Influence of synthesis temperature}

The main porous properties of the carbon xerogels synthesized at $75^{\circ} \mathrm{C}$ and $85^{\circ} \mathrm{C}$ for three different values of $t_{\mathrm{g}-\mathrm{a}}$ are reported in Table 4 . The porosity of the samples is not greatly affected by the temperature variation studied in this work, i.e. $10^{\circ} \mathrm{C}$. This may be due to the fact that there was no significant variation in the gelation point with the variation in temperature: 1320 and 900 seconds at 75 and $85^{\circ} \mathrm{C}$, respectively (Table 2). As mentioned above, temperature and $t_{\mathrm{g}-\mathrm{a}}$ are not independent variables in relation to porous textural properties. Hence, the possible interaction between these variables was evaluated by applying the response surface methodology approach.

\subsection{Response surface methodology (RSM) and statistical analysis}

The implementation of RSM allows the interaction between temperature and $t_{\mathrm{g}-\mathrm{a}}$ and their effect on the main porous properties to be evaluated with a minimum number of experiments. An analysis of variance (ANOVA) for each response was performed in order to determine whether the model selected was sufficiently significant to fit the experimental results. The central composite design was used as the experimental design. The significance of each input variable and its interaction was determined by evaluating the $\mathrm{p}$-value. If $\mathrm{p}$-values are smaller than 0.05 the corresponding variable will have a significant effect on the response. In this study, the RSM statistical analysis showed an adequate fit of a quadratic function type.

\subsubsection{Effect on the microporosity}

The ANOVA results applied to microporosity indicate that time and temperature were important factors in the model. However, the interaction between these two variables was not an important factor as the p-value was 0.2432 . An R-squared value of 0.9952 was obtained, which is very close to the predicted R-squared value of 0.9477 , indicating the adequacy of the model. Figure 4 shows the contour line plot corresponding to the 
effect of $t_{g-a}$ and temperature on the microporosity. From the contour plot it can be inferred that, under the conditions studied, $\mathrm{tg}_{\mathrm{g}-\mathrm{a}}$ has a greater effect than the variation in temperature.

\subsubsection{Effect on the total pore volume}

The model was also found suitable for the total pore volume. An R-squared value of 0.9881 was obtained, which is very close to the predicted R-squared value of 0.8403 again indicating the adequacy of the model. The p-values obtained show that temperature is not a significant model term, while the second order effect of $t_{\mathrm{g}-\mathrm{a}}$ is an important factor that affects the model. In fact, the total pore volume increases by $40 \%$ when the time is increased from 2000 to 6000 seconds. Then it decreases when time is increased to 10000 seconds. Figure 5 shows the effect of both time and temperature on the total pore volume.

\subsubsection{Effect on the mean pore size}

The ANOVA results applied to the mean pore size indicate that $\mathrm{t}_{\mathrm{g}-\mathrm{a}}$ and its second order effect are significant model terms with p-values of 0.0438 and 0.0214 , respectively. The R-squared and predicted R-squared values were 0.9957 and 0.9531, respectively, indicating the good predictive capacity of the model. The evolution of pore size with time and temperature can be inferred from Figure 6.

\section{Discussion}

The transfer of microwave-assisted technology for the production of carbon xerogels to an industrial scale requires the study of the effect of the operational variables on the final porous properties of the material.

Using 30ml of precursor solution leads to a less developed material than that obtained with higher volumes of solution. This may be due to the excess of power used in the microwave oven for such a small volume of precursor solution. However, samples synthesized from 200 and $3000 \mathrm{ml}$ of solution exhibit isotherms that are almost superimposed, suggesting that the development of porosity can be fully controlled even with a high initial volume of precursor solution. In addition, the development of 
porosity in these carbon xerogels with microwave heating is analogous to that obtained in a conventional oven, as already reported in previous works [29].

Furthermore, by decreasing the energy consumed per volume unit it is possible to enhance the porous development of the samples. But the fact that the samples synthesized from 200 and 3000ml exhibit a similar porous structure indicates that a decrease to below $1100 \mathrm{~kJ} / \mathrm{l}$ in the microwave energy consumed will not lead to any further development of porosity. From these results it can be inferred that it is possible to synthesize a high amount of xerogel using less microwave energy and at the same time maintain the structural properties. This will result in a reduction in energy costs and a more competitive process. Thus, the application of microwave-assisted synthesis of carbon xerogel on an industrial scale appears feasible provided the energy consumed per volume unit is correctly chosen.

When these samples were carbonised their microporosity increased, whereas the mesopore volume decreased. These results are in accordance with those of previous works where it was demonstrated that during carbonization volatiles are released, leading to the formation of new micropores and to the reduction in size of some pores owing to the partial collapse of the pore structure [2]. The combination of both factors (micropore formation and the decrease in mesopore size) led to an increase in microporosity and a narrower mesopore size distribution, both in the case of the conventional carbon xerogels widely presented in the bibliography and in the case of the carbon xerogels obtained by microwave heating presented in this work.

Since the samples synthesized at $\mathrm{pH}$ of 6.5 from a $200 \mathrm{ml}$ initial volume of precursor exhibited a well-developed porous structure, this value was chosen to study the influence of the gelation and ageing time $\left(\mathrm{t}_{\mathrm{g}-\mathrm{a}}\right)$ and temperature of synthesis. For both synthesis temperatures, 75 and $85^{\circ} \mathrm{C}$, the samples with a $t_{\text {g-a }}$ of 6000 seconds exhibited the highest volume of mesopores. The maximum porous development was achieved when the time, $t_{\mathrm{g}-\mathrm{a}}$, was fixed at an intermediate value. This can be attributed to the microwave energy consumed during the synthesis process, as explained below.

The amount of energy consumed by the microwave device varies depending on the dielectric properties of the material to be heated [37]. In the case of organic gels 
synthesis, these dielectric properties change during the process and therefore the energy consumed by the microwave oven depends on the stage of synthesis [38]. In the present work, the accumulative energy consumed by the microwave device was measured as a function of gelation and ageing time $\left(\mathrm{t}_{\mathrm{g}-\mathrm{a}}\right)$. Given that the representations are similar for all the xerogels studied, only the one corresponding to sample OX-200-10000-75 is shown here as an example (Figure 7).

Figure 7 shows five straight lines of different slope. The first one corresponds to the increase in temperature up to the set point was reached (58 seconds); the second one represents the stabilization of the temperature (3-4 minutes) and the third line indicates the sol-gel reactions step. The crosslinking and the secondary reactions take place during the transition from the sol to the gel up to the point where a stable solid material is formed. The third change in slope shown in Figure 7 (i.e. 1320 seconds) corresponds to the gelation point, which was also determined by visual observation (1680 and 1080 seconds for the samples synthesized at 75 and $85^{\circ} \mathrm{C}$, respectively, as shown in Table 3). Under the conditions established for this study, the gelation times obtained visually are longer than those obtained by measuring the change in the slope of energy consumption because the transition from gel to sol occurs gradually and is difficult to determine visually. This phenomenon is consistent with another published study where differences in the gelation time obtained by rheology and visually were reported [34]. However, the methodology followed in the present work allows the gelation point to be determined inside the synthesis device, i.e. without the need for any additional technique.

According to the changes in slope shown in Figure 7, a $\mathrm{t}_{\mathrm{g}-\mathrm{a}}$ of 2000 seconds is not long enough for the crosslinking and the secondary reactions to be concluded. The result is a material with poorly connected primary particles and small weakly linked aggregates of nodules [33]. During the drying stage the material cannot withstand the surface tensions and probably undergoes further shrinkage [2]. These samples, regardless of the synthesis temperature, correspond to an unstable material with weakly linked clusters. During drying the shrinkage increases and the carbonised materials exhibit a porous structure that is less developed than the porosity of those synthesized for a longer time (Figure 3) 
Once a stable solid material is obtained, it is necessary to remove the solvent by drying. However, during the synthesis process itself, partial evaporation of the dissolvent occurs while the ageing process continues. At this point, when the ageing stage and partial evaporation are taking place simultaneously, more energy is required to maintain the programmed temperature [29]. This phenomenon is consistent with Figure 7, where a change in slope appears at around 58 minutes (i.e. 3500 seconds). During the partial evaporation of the solvent the material undergoes shrinkage. The longer the partial evaporation stage lasts, the greater the shrinkage of the material, as a consequence of which the volume of mesopores decreases. This is also in agreement with the nitrogen adsorption-desorption isotherms shown in Figure 3, where samples synthesized for 6000 seconds show a higher mesoporosity development than those synthesized for 10000 , regardless of the synthesis temperature.

It should be noted that, although ageing and partial drying occur simultaneously, all the samples studied were subjected to an exclusive drying stage at $85^{\circ} \mathrm{C}$ after synthesis, until a mass loss of more than 50\% was achieved. The time needed for drying depends on the ageing time, and consequently on the $t_{\text {g-a }}$. High values of $t_{\text {g-a }}$ lead to materials with more strongly linked aggregates [33]. The structure of these stable solid materials impedes the evaporation of the solvent, with the result that the drying time needs to be longer (Table 3).

Regarding the influence of the synthesis temperature, it can be concluded that the porosity of the samples is not greatly affected by the temperature variation used in this work, i.e. $10^{\circ} \mathrm{C}$. These results are in agreement with those reported by Job et al. (2006) where no significant influence on the final properties of carbon xerogel synthesized from a precursor solution with a $\mathrm{pH}$ of 6.5 was observed when the temperature was increased from 70 to $90^{\circ} \mathrm{C}$ in a conventional oven.

The fact that a change in temperature of $10^{\circ} \mathrm{C}$ has no effect on the final porous properties is due to the non-significant variation in the gelation point, as shown in Table 2. These results were corroborated by the implementation of RSM, which showed that the interaction between these variables had a negligible effect on the porous properties under the synthesis conditions studied. 
With respect to the porous properties, only a very slight effect on the microporosity was observed in the range of $t_{\mathrm{g}-\mathrm{a}}$ and temperature of synthesis studied. These results are in accordance with other studies reported where no increase in microporosity development occurred when the synthesis conditions were modified in conventional synthesis [35]. The effect of the variables studied was a little more pronounced in the case of the total pore volume, which increased by $40 \%$ with the increase in time from 2000 to 6000 seconds. The pore size range of all the samples studied was between 7 and $10 \mathrm{~nm}$ and therefore the effect of both input variables on the pore size can be considered negligible. These negligible effects on the porous properties, when the time and temperature of synthesis vary, represent a great advantage for scaling up the production of carbon xerogels.

\section{Conclusions}

The influence of the operational variables on the final porous properties of carbon xerogels was studied. The results show that by means of microwave-assisted synthesis it is possible to synthesize organic xerogel from $3000 \mathrm{ml}$ of precursor solution, and produce a material with a well-developed and controlled porous structure. Furthermore, if a higher volume of precursor solution is used, the energy consumption per volume unit was lower than that needed for smaller initial volumes of precursor solution.

The time needed to complete the gelation and ageing stages plays an important role in the final porous properties. Both short and long times, i.e. 2000 and 10000 seconds, respectively, lead to materials in which the carbon structure collapses and the development of porosity decreases. Optimization of the gelation and ageing time seems to be the key to controlling porosity.

Furthermore, the porous properties of carbon xerogels prepared by microwave synthesis show little susceptibility to the temperature variation in the range studied, i. e. $75-85^{\circ} \mathrm{C}$. Very little interaction between temperature and gelation time was observed in the operating conditions studied. All of the results obtained indicate that the synthesis of carbon xerogels by microwave radiation produces materials analogous to those obtained by conventional synthesis, via a process that is considerably more cost-effective, as only 
one device and moderate conditions are needed. Thus, the production of carbon xerogels on an industrial scale appears feasible.

\section{Acknowledgements}

Financial support from the Ministerio de Economía y Competitividad of Spain MINECO (under Projects MAT2011-23733 and IPT-2012-0689-420000) is greatly acknowledged. NRR is also grateful to MINECO for her predoctoral research grant.

\section{References}

1. Al-Muhtaseb SA, Ritter JA (2003) Preparation and properties of resorcinolformaldehyde organic and carbon gels. Adv Mater 15 (2):101-114

2. Job N, Théry A, Pirard R, Marien J, Kocon L, Rouzaud J-N, Béguin F, Pirard J-P (2005) Carbon aerogels, cryogels and xerogels: Influence of the drying method on the textural properties of porous carbon materials. Carbon 43 (12):2481-2494

3. Girgis BS, El-Sherif IY, Attia AA, Fathy NA (2012) Textural and adsorption characteristics of carbon xerogel adsorbents for removal of $\mathrm{Cu}$ (II) ions from aqueous solution. J Non-Cryst Solids 358 (4):741-747

4. Yamamoto T, Endo A, Ohmori T, Nakaiwa M (2004) Porous properties of carbon gel microspheres as adsorbents for gas separation. Carbon 42 (8-9):1671-1676

5. Lu X, Caps R, Fricke J, Alviso CT, Pekala RW (1995) Correlation between structure and thermal conductivity of organic aerogels. J Non-Cryst Solids 188 (3):226-234

6. Wiener M, Reichenauer G, Braxmeier S, Hemberger F, Ebert HP (2009) Carbon aerogel-based high-temperature thermal insulation. Int J Thermophys 30 (4):1372-1385

7. Alegre C, Gálvez ME, Baquedano E, Pastor E, Moliner R, Lázaro MJ (2012) Influence of support's oxygen functionalization on the activity of Pt/carbon xerogels catalysts for methanol electro-oxidation. Int J Hydrogen Energy 37 (8):7180-7191

8. Samant PV, Fernandes JB, Rangel CM, Figueiredo JL (2005) Carbon xerogel supported Pt and Pt-Ni catalysts for electro-oxidation of methanol in basic medium. Catal Today 102-103:173-176

9. Calvo EG, Lufrano F, Staiti P, Brigandì A, Arenillas A, Menéndez JA (2013) Optimizing the electrochemical performance of aqueous symmetric supercapacitors based on an activated carbon xerogel. J Power Sources 
10. Halama A, Szubzda B, Pasciak G (2010) Carbon aerogels as electrode material for electrical double layer supercapacitors - Synthesis and properties. Electrochim Acta 55 (25):7501-7505

11. Job N, Marie J, Lambert S, Berthon-Fabry S, Achard P (2008) Carbon xerogels as catalyst supports for PEM fuel cell cathode. Energy Conversion and Management 49 (9):2461-2470

12. Liu B, Creager S (2010) Carbon xerogels as Pt catalyst supports for polymer electrolyte membrane fuel-cell applications. J Power Sources 195 (7):1812-1820

13. Chao YJ, Yuan X, Ma ZF (2008) Preparation and characterization of carbon cryogel (CC) and CC-SiO composite as anode material for lithium-ion battery. Electrochim Acta 53 (9):3468-3473

14. Mirzaeian M, Hall PJ (2009) Preparation of controlled porosity carbon aerogels for energy storage in rechargeable lithium oxygen batteries. Electrochim Acta 54 (28):7444-7451

15. Pekala RW (1989) Organic aerogels from the polycondensation of resorcinol with formaldehyde. Journal of Materials Science 24 (9):3221-3227

16. Czakkel O, Marthi K, Geissler E, László K (2005) Influence of drying on the morphology of resorcinol-formaldehyde-based carbon gels. Microporous Mesoporous Mater 86 (1-3):124-133

17. Fu R, Zheng B, Liu J, Weiss S, Ying JY, Dresselhaus MS, Dresselhaus G, Satcher Jr JH, Baumann TF (2003) Fabrication of activated carbon fibers/carbon aerogels composites by gelation and supercritical drying in isopropanol. J Mater Res 18 (12):2765-2773

18. Wu D, Fu R, Yu Z (2005) Organic and carbon aerogels from the NaOH-catalyzed polycondensation of resorcinol-furfural and supercritical drying in ethanol. J Appl Polym Sci 96 (4):1429-1435

19. Kraiwattanawong K, Tamon H, Praserthdam P (2011) Influence of solvent species used in solvent exchange for preparation of mesoporous carbon xerogels from resorcinol and formaldehyde via subcritical drying. Microporous Mesoporous Mater $138(1-3): 8-16$

20. Yamamoto T, Nishimura T, Suzuki T, Tamon H (2001) Control of mesoporosity of carbon gels prepared by sol-gel polycondensation and freeze drying. Journal of NonCrystalline Solids 288 (1-3):46-55 
21. Job N, Sabatier F, Pirard JP, Crine M, Léonard A (2006) Towards the production of carbon xerogel monoliths by optimizing convective drying conditions. Carbon 44 (12):2534-2542

22. Conceição FL, Carrott PJM, Ribeiro Carrott MML (2009) New carbon materials with high porosity in the $1-7 \& \# \mathrm{xa} 0$;nm range obtained by chemical activation with phosphoric acid of resorcinol-formaldehyde aerogels. Carbon 47 (7):1874-1877

23. Contreras MS, Páez CA, Zubizarreta L, Léonard A, Blacher S, Olivera-Fuentes CG, Arenillas A, Pirard J-P, Job N (2010) A comparison of physical activation of carbon xerogels with carbon dioxide with chemical activation using hydroxides. Carbon 48 (11):3157-3168

24. Lin C, Ritter JA (2000) Carbonization and activation of sol-gel derived carbon xerogels. Carbon 38 (6):849-861

25. Zubizarreta L, Arenillas A, Pirard J-P, Pis JJ, Job N (2008) Tailoring the textural properties of activated carbon xerogels by chemical activation with $\mathrm{KOH}$. Microporous Mesoporous Mater 115 (3):480-490

26. Qin G, Wei W, Guo S (2003) Semi-continuous drying of RF gels with supercritical acetone. Carbon 41 (4):851-853

27. Zubizarreta L, Arenillas A, Menéndez JA, Pis JJ, Pirard JP, Job N (2008) Microwave drying as an effective method to obtain porous carbon xerogels. J Non-Cryst Solids 354 (33):4024-4026

28. Tonanon N, Wareenin Y, Siyasukh A, Tanthapanichakoon W, Nishihara H, Mukai SR, Tamon H (2006) Preparation of resorcinol formaldehyde (RF) carbon gels: Use of ultrasonic irradiation followed by microwave drying. J Non-Cryst Solids 352 (5254):5683-5686

29. Calvo EG, Juárez-Pérez EJ, Menéndez JA, Arenillas A (2011) Fast microwaveassisted synthesis of tailored mesoporous carbon xerogels. Journal of Colloid and Interface Science 357 (2):541-547

30. Elkhatat AM, Al-Muhtaseb SA (2011) Advances in tailoring resorcinolformaldehyde organic and carbon gels. Advanced Materials 23 (26):2887-2903

31. Li J, Wang X, Wang Y, Huang Q, Dai C, Gamboa S, Sebastian PJ (2008) Structure and electrochemical properties of carbon aerogels synthesized at ambient temperatures as supercapacitors. J Non-Cryst Solids 354 (1):19-24 
32. Job N, Panariello F, Marien J, Crine M, Pirard J-P, Léonard A (2006) Synthesis optimization of organic xerogels produced from convective air-drying of resorcinolformaldehyde gels. J Non-Cryst Solids 352 (1):24-34

33. Wiener M, Reichenauer G, Scherb T, Fricke J (2004) Accelerating the synthesis of carbon aerogel precursors. J Non-Cryst Solids 350 (0):126-130

34. Job N, Panariello F, Crine M, Pirard J-P, Léonard A (2007) Rheological determination of the sol-gel transition during the aqueous synthesis of resorcinolformaldehyde resins. Colloids Surf, A 293 (1-3):224-228

35. Gallegos-Suárez E, Pérez-Cadenas AF, Maldonado-Hódar FJ, Carrasco-Marín F (2012) On the micro- and mesoporosity of carbon aerogels and xerogels. The role of the drying conditions during the synthesis processes. Chem Eng J 181-182:851-855

36. Pérez-Caballero F, Peikolainen AL, Koel M (2008) Preparation of nanostructured carbon materials. Proceedings of the Estonian Academy of Sciences 57 (1):48-53

37. Menéndez JA, Arenillas A, Fidalgo B, Fernández Y, Zubizarreta L, Calvo EG, Bermúdez JM (2010) Microwave heating processes involving carbon materials. Fuel Processing Technology 91 (1):1-8

38. Juárez-Pérez EJ, Calvo EG, Arenillas A, Menéndez JA (2010) Precise determination of the point of sol-gel transition in carbon gel synthesis using a microwave heating method. Carbon 48 (11):3305-3308

39. Moreno AH, Arenillas A, Calvo EG, Bermúdez JM, Menéndez JA (2013) Carbonisation of resorcinol-formaldehyde organic xerogels: Effect of temperature, particle size and heating rate on the porosity of carbon xerogels. J Anal Appl Pyrolysis 100:111-116 


\section{TABLE CAPTIONS}

Table 1. Porous properties of organic and carbon xerogels synthesized by using different initial volumes

Table 2. Time and energy consumed during the microwave-assisted synthesis of organic xerogels

Table 3. Time needed to complete each synthesis stage

Table 4. Main porous properties of carbon xerogels synthesized at $75^{\circ} \mathrm{C}$ and $85^{\circ} \mathrm{C}$ 
Table 1. Porous properties of organic and carbon xerogels synthesized by using different initial volumes

\begin{tabular}{ccccc}
\hline Samples & $\begin{array}{c}\mathrm{S}_{\mathrm{BET}}\left(\mathrm{m}^{2} / \mathrm{g}\right) \\
\pm 0.5\end{array}$ & $\begin{array}{c}\mathrm{V}_{\text {DUB }}\left(\mathrm{cm}^{3} / \mathrm{g}\right) \\
\pm 0.01\end{array}$ & $\begin{array}{c}\mathrm{V}_{\mathrm{P}}\left(\mathrm{cm}^{3} / \mathrm{g}\right) \\
\pm 0.06\end{array}$ & $\begin{array}{c}\mathrm{D}_{\mathrm{p}}(\mathrm{nm}) \\
\pm 1\end{array}$ \\
\hline OX-30-10000-85 & 227 & 0.08 & 0.34 & 8 \\
OX-200-10000-85 & 398 & 0.14 & 0.51 & 10 \\
OX-3000-10000-85 & 413 & 0.15 & 0.54 & 10 \\
\hline CX-30-10000-85 & 535 & 0.21 & 0.36 & 9 \\
CX-200-10000-85 & 643 & 0.24 & 0.56 & 9 \\
CX-3000-10000-85 & 619 & 0.23 & 0.62 & 8 \\
\hline
\end{tabular}


Table 2. Time and energy consumed during the microwave-assisted synthesis of organic xerogels

\begin{tabular}{lccc}
\hline & OX-30-10000-85 & OX-200-10000-85 & OX-3000-10000-85 \\
\hline Time for set point-T (s) & $50 \pm 20$ & $78 \pm 20$ & $1115 \pm 20$ \\
Time of synthesis, $\mathrm{t}_{\mathrm{s}}(\mathrm{s})$ & $19020 \pm 60$ & $22600 \pm 60$ & $23700 \pm 60$ \\
Energy consumed $(\mathrm{kJ} / \mathrm{l})$ & $43300 \pm 50$ & $8500 \pm 500$ & $1100 \pm 50$ \\
\hline
\end{tabular}


Table 3. Time needed to complete each synthesis stage

\begin{tabular}{cccccc}
\hline Samples & $\begin{array}{c}\text { Gelation time } \\
\text { (visual } \\
\text { observation), } \\
\mathrm{tg}_{\mathrm{g}}(\mathrm{s}) \pm 60\end{array}$ & $\begin{array}{c}\text { Gelation time } \\
\text { (change in the } \\
\text { slope), } \mathrm{t}_{\mathrm{g}}(\mathrm{s}) \\
\pm 90\end{array}$ & $\begin{array}{c}\text { Ageing } \\
\text { time, } \mathrm{t}_{\mathrm{a}} \\
(\mathrm{s})\end{array}$ & $\begin{array}{c}\text { Drying } \\
\text { time (s) }\end{array}$ & $\begin{array}{c}\text { Total } \\
\text { synthesis } \\
\text { time (s) }\end{array}$ \\
\hline CX-200-2000-75 & 1680 & 1320 & 680 & 7200 & 9200 \\
CX-200-6000-75 & 1680 & 1320 & 4680 & 14400 & 20400 \\
CX-200-10000-75 & 1680 & 1320 & 8680 & 10800 & 20800 \\
\hline CX-200-2000-85 & 1080 & 900 & 1100 & 9000 & 11000 \\
CX-200-6000-85 & 1080 & 900 & 5100 & 12600 & 18600 \\
CX-200-10000-85 & 1080 & 900 & 9100 & 12600 & 22600 \\
\hline
\end{tabular}


Table 4. Main porous properties of carbon xerogels synthesized at $75^{\circ} \mathrm{C}$ and $85^{\circ} \mathrm{C}$

\begin{tabular}{ccccc}
\hline Samples & $\begin{array}{c}\mathrm{S}_{\mathrm{BET}}\left(\mathrm{m}^{2} / \mathrm{g}\right) \\
\pm 0.5\end{array}$ & $\begin{array}{c}\mathrm{V}_{\text {DUB }}\left(\mathrm{cm}^{3} / \mathrm{g}\right) \\
\pm 0.01\end{array}$ & $\begin{array}{c}\mathrm{V}_{\mathrm{P}}\left(\mathrm{cm}^{3} / \mathrm{g}\right) \\
\pm 0.06\end{array}$ & $\begin{array}{c}\mathrm{D}_{\mathrm{p}}(\mathrm{nm}) \\
\pm 1\end{array}$ \\
\hline CX-200-2000-75 & 578 & 0.22 & 0.44 & 7 \\
$\mathrm{CX}-200-2000-85$ & 617 & 0.23 & 0.46 & 7 \\
\hline CX-200-6000-75 & 660 & 0.25 & 0.63 & 10 \\
$\mathrm{CX}-200-6000-85$ & 684 & 0.26 & 0.71 & 10 \\
\hline CX-200-10000-75 & 635 & 0.24 & 0.52 & 8 \\
$\mathrm{CX}-200-10000-85$ & 655 & 0.25 & 0.60 & 9 \\
\hline
\end{tabular}




\section{FIGURE CAPTIONS}

Figure 1. $\mathrm{N}_{2}$ adsorption-desorption isotherms of organic (a) and carbon (b) xerogels synthesized using different initial volumes of precursor solution

Figure 2. Pore size distribution of organic (a) and carbon (b) xerogels synthesized using different initial volumes of precursor solution

Figure 3. $\mathrm{N}_{2}$ adsorption-desorption isotherms of carbon xerogels synthesized at $75^{\circ} \mathrm{C}$ (a) and $85^{\circ} \mathrm{C}(\mathrm{b})$

Figure 4. Variation of the volume of micropores with $t_{\mathrm{g}-\mathrm{a}}$ and temperature of synthesis

Figure 5. Evolution of the total volume of pores with $t_{\mathrm{g}-\mathrm{a}}$ and temperature of synthesis

Figure 6. Evolution of pore size with $\mathrm{t}_{\mathrm{g}-\mathrm{a}}$ and temperature of synthesis

Figure 7. Microwave energy consumption vs. time of gelation and ageing (sample OX200-10000-75) 

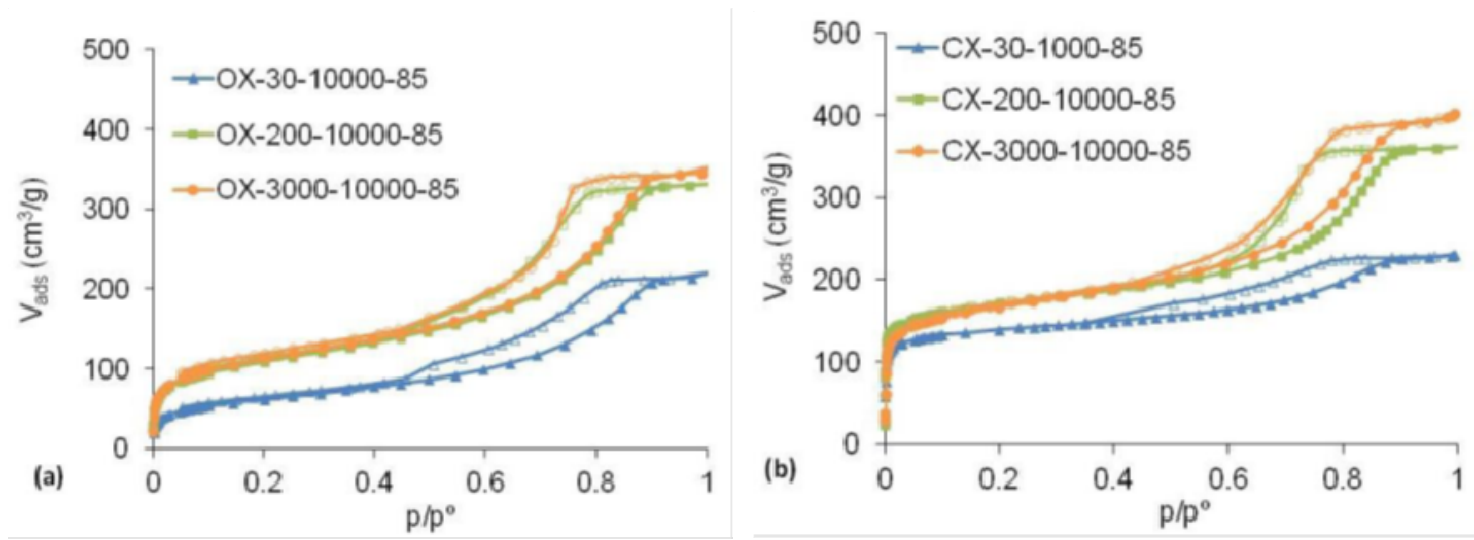

Figure 1. $\mathrm{N}_{2}$ adsorption-desorption isotherms of organic (a) and carbon (b) xerogels synthesized using different initial volumes of precursor solution 

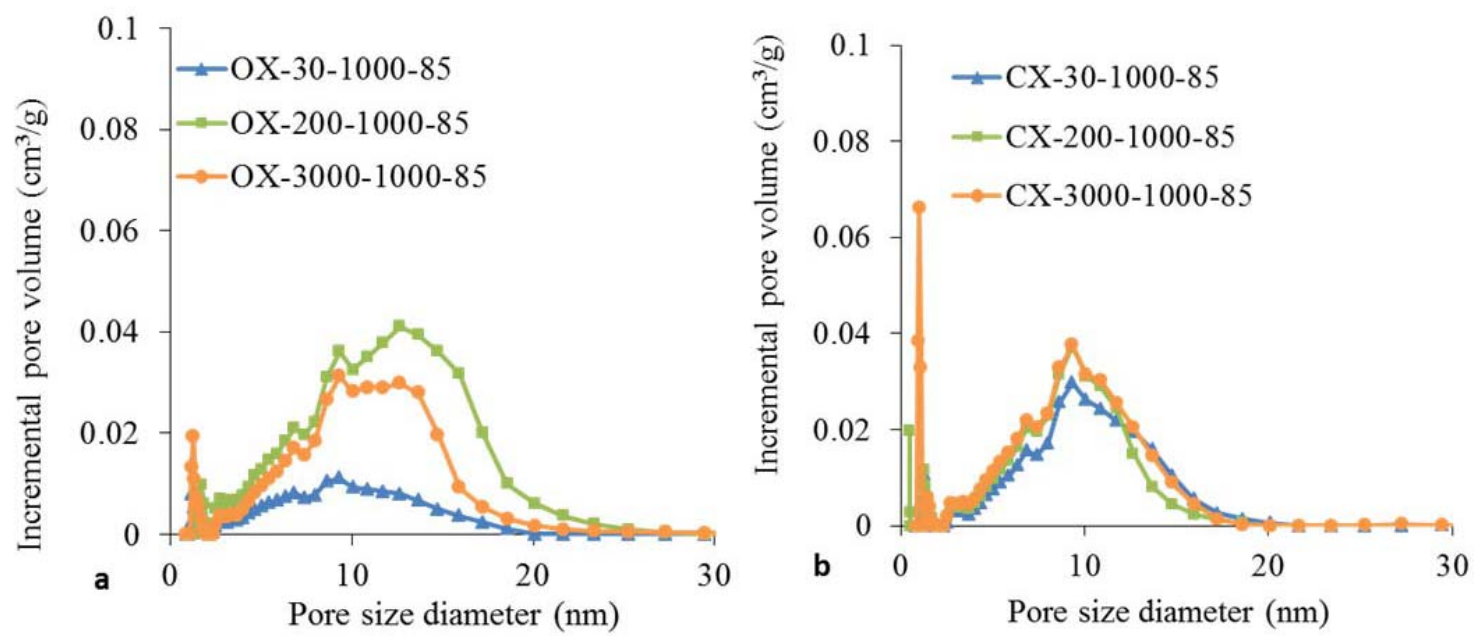

Figure 2. Pore size distribution of organic (a) and carbon (b) xerogels synthesized using different initial volume of precursor solution 

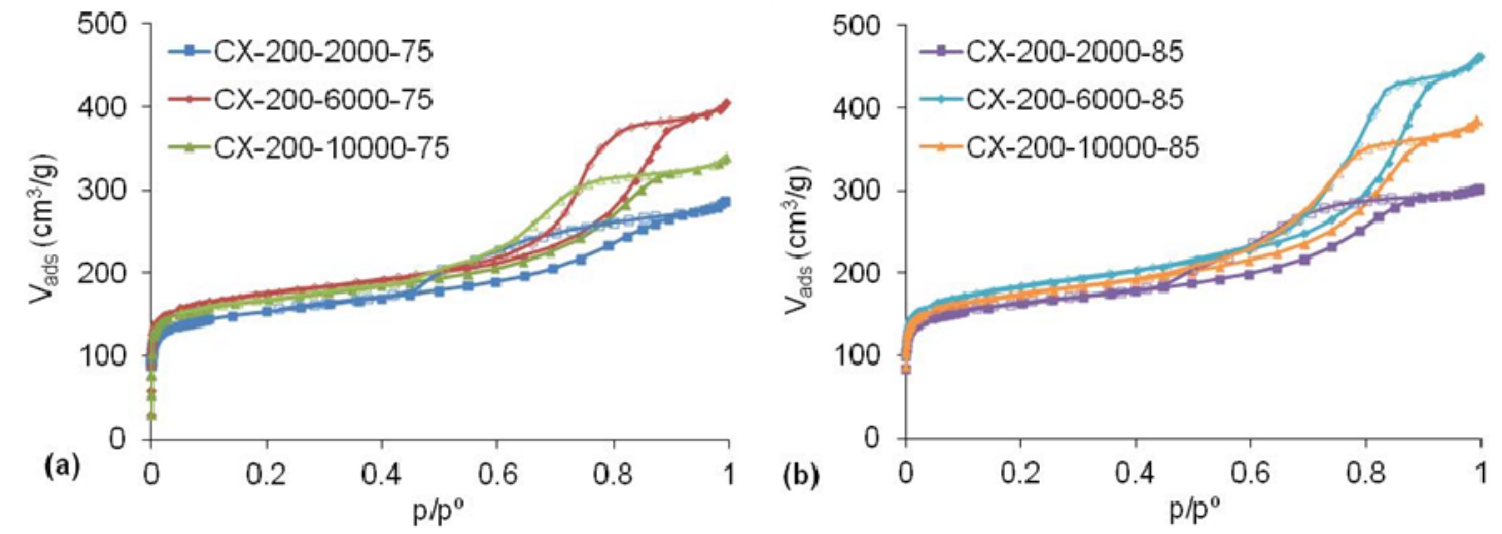

Figure 3. $\mathrm{N}_{2}$ adsorption-desorption isotherms of carbon xerogels synthesized at $75^{\circ} \mathrm{C}$ (a) and $85^{\circ} \mathrm{C}$ (b) 


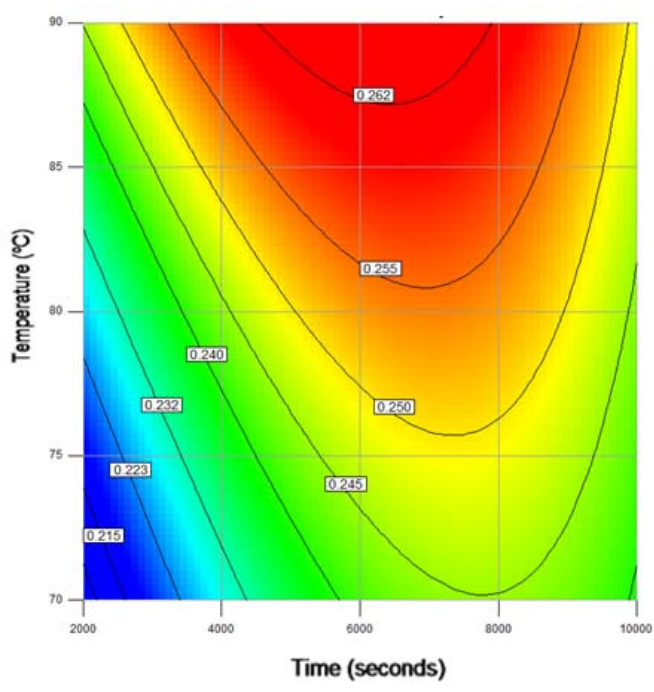

Figure 4. Variation of the volume of micropores with $\mathrm{t}_{\mathrm{g}-\mathrm{a}}$ and temperature of synthesis 


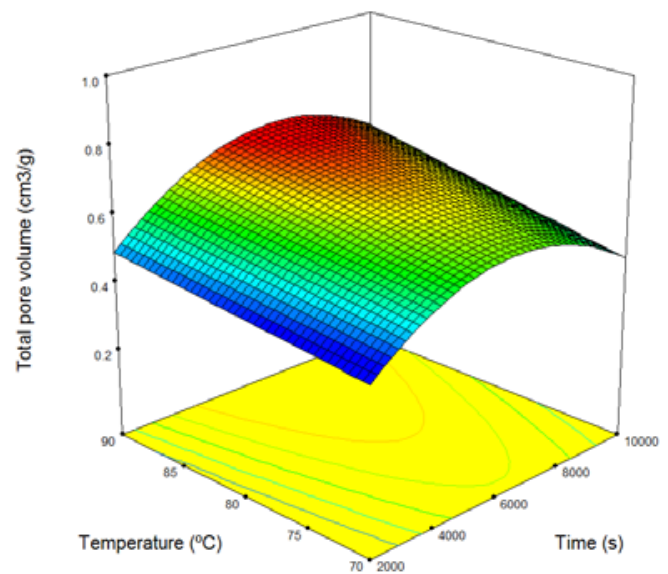

Figure 5. Evolution of the total volume of pores with $t_{\mathrm{g}-\mathrm{a}}$ and temperature of synthesis 


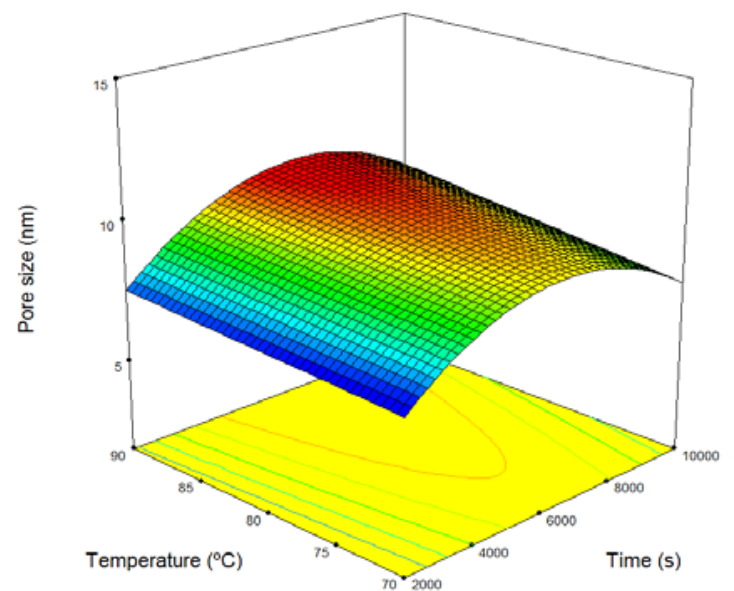

Figure 6. Evolution of pore size with $\mathrm{t}_{\mathrm{g}-\mathrm{a}}$ and temperature of synthesis 


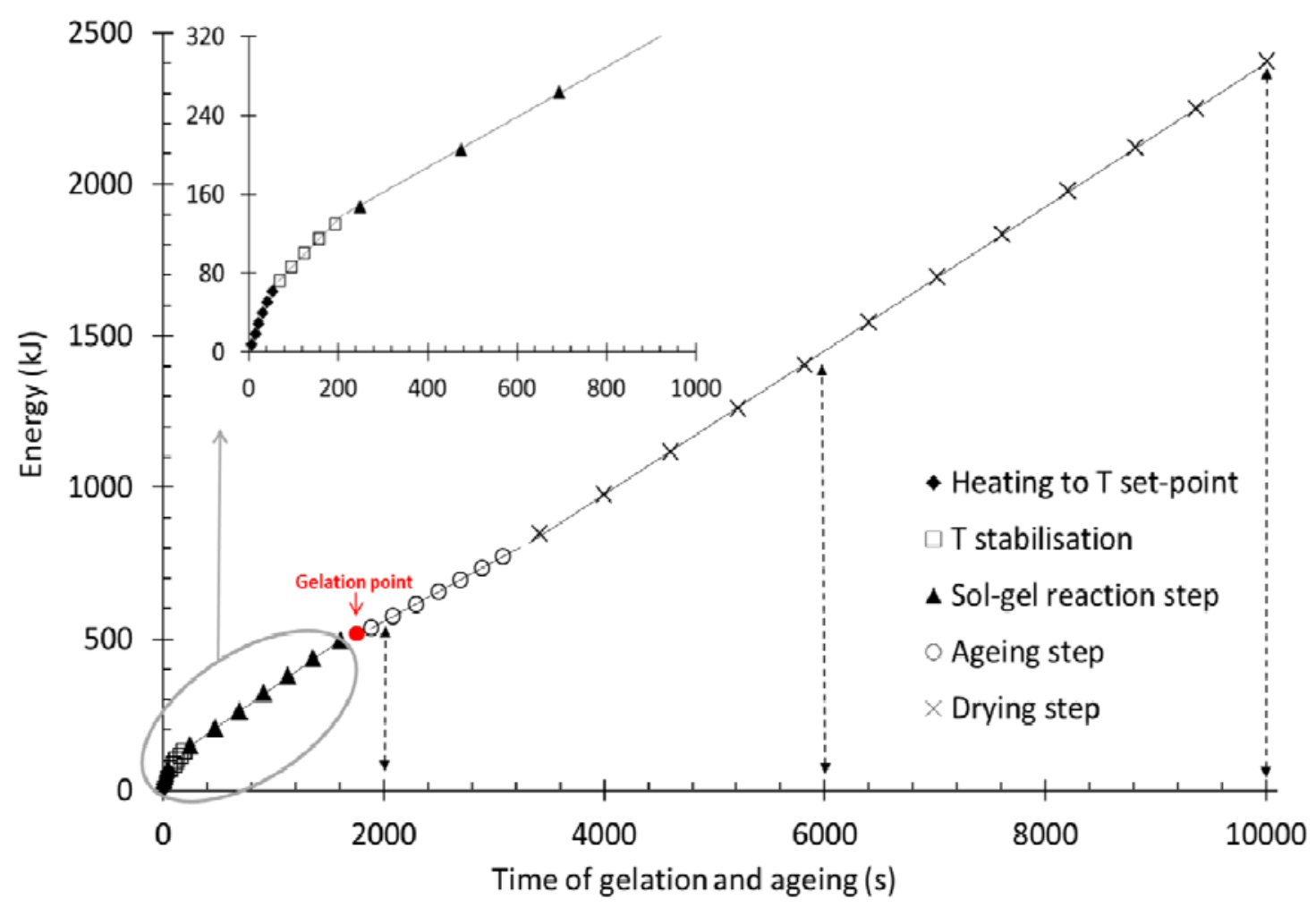

Figure 7. Microwave energy consumption vs. time of gelation and ageing (sample OX200-10000-75) 